\title{
Relationships between Body Build and Knee Joint Flexor and Extensor Torque of Polish First-Division Soccer Players
}

\author{
Jadwiga Pietraszewska ${ }^{1}$, Artur Struzik ${ }^{2, *}{ }^{\oplus}$, Anna Burdukiewicz ${ }^{1}$, Aleksandra Stachon ${ }^{1}$ and \\ Bogdan Pietraszewski ${ }^{3}$ \\ 1 Department of Physical Anthropology, University School of Physical Education, Paderewskiego 35 Avenue, \\ 51-612 Wrocław, Poland; jadwiga.pietraszewska@awf.wroc.pl (J.P.); anna.burdukiewicz@awf.wroc.pl (A.B.); \\ aleksandra.stachon@awf.wroc.pl (A.S.) \\ 2 Department of Team Sport Games, University School of Physical Education, Mickiewicza 58 Street, \\ 51-684 Wrocław, Poland \\ 3 Department of Biomechanics, University School of Physical Education, Mickiewicza 58 Street, \\ 51-684 Wrocław, Poland; bogdan.pietraszewski@awf.wroc.pl \\ * Correspondence: artur.struzik@awf.wroc.pl; Tel.: +48-71-347-35-61
}

Received: 18 December 2019; Accepted: 20 January 2020; Published: 22 January 2020

Featured Application: Body height, body mass and thigh and calf girths are the anthropometric variables that best describe the values of the torque of the knee flexors and extensors that can be achieved by soccer players. Based on these anthropometric variables, the coach can initially assess players' strength abilities, which can help plan individual training programmes.

\begin{abstract}
The aim of the study is to identify the relationships between anthropometric variables and knee joint extensor peak torque, knee joint flexor peak torque, and conventional hamstring-to-quadriceps ratio in Polish first-division soccer players. The study examined 37 soccer players aged 19 to 30 years (body mass: $76.8 \pm 7.2 \mathrm{~kg}$, body height $1.82 \pm 0.06 \mathrm{~m}$ ). Muscle torques of the knee joint were measured under isometric conditions using a Biodex 4 Pro dynamometer. The anthropometric variables such as body part lengths, breadths, and girths and skinfold thickness were measured. The strongest relationships of knee joint extensors were observed with body mass and variables describing skeleton size and lower-limb muscles. Regarding knee flexor torque, a significant relationship was found only with body mass. However, no significant relationships were observed between the conventional hamstring-to-quadriceps ratio and the anthropometric variables studied. The regression analysis results identified body height, body mass, and thigh and calf girth as the features most associated with knee joint torque. However, anthropometric measurements do not provide full information about the torque proportions of antagonist muscle groups, which is very important for injury prevention. Therefore, measurements using special biomechanical equipment are also necessary for the comprehensive analyses and control of the effects of sports training.
\end{abstract}

Keywords: anthropometric variables; hamstring-to-quadriceps ratio; $\mathrm{H} / \mathrm{Q}$ ratio; injury prevention; isometric; lower limb; measurement acquisitions and techniques; strength and conditioning; sports training; strength abilities

\section{Introduction}

Measurements of muscle torque taken in isometric and isokinetic conditions have often been used for sports training [1-5]. Coaches use biomechanical measurement tools to analyse the sports skill level of athletes, improve movement techniques, or adjust tactics against the opponent $[6,7]$. 
Biomechanical analysis provides a fast and reliable evaluation of torque values, helps detect muscle strength imbalance, and screens for lower extremity injury $[8,9]$. Numerous studies have focused on the evaluation of the value of muscle torque in relation to lower limbs, which are particularly involved during sports movements. Appropriate force and proportion between antagonistic muscle groups are essential for optimal or maximum performance of various movements, which is also true in team sport games [10-14]. The dependence of force on the transverse cross-sectional area of muscles is known, but it should be noted that force is also affected by other factors related to the efficiency of the nervous system (that controls muscle function) and the properties of the muscles themselves [15].

Soccer is a sport in which the requirements for effective play are multi-factorial. The intervals and repetitive nature of the efforts during the match mean that the competitors should demonstrate adequate speed, endurance, strength, and coordination levels. In general, the players do not reach the highest levels of all these motor abilities. However, they must demonstrate a sufficiently high level of preparation in all aspects of motor abilities, with the dominance of some of them (depending on their playing position). Interindividual differences can also be observed in the anthropometric characteristics of soccer players [16]. In soccer, the lower limbs are particularly involved when kicking the ball, striking at a goal, and running at different velocities and with directional changes [17-20]. Soccer training is aimed, among other things, at increasing muscle mass and, consequently, muscle force. The adequate level of force of the knee extensors and flexors allows the player to achieve stronger strikes, jump higher, and sprint faster over short distances [21-23].

In addition to the absolute values of the generated torque, the correct ratio of the torque of extensors to that of flexors is also important. The commonly used conventional hamstring-to-quadriceps ratio $(\mathrm{H} / \mathrm{Q}$ ratio) represents the ratio of concentric hamstring peak torque during lower limb flexion to concentric quadriceps peak torque during lower limb extension [24]. The functional hamstring-to-quadriceps ratio, in contrast, is a measure of the isokinetic eccentric peak torque of the hamstrings relative to the isokinetic concentric peak torque of the quadriceps during lower limb extension at equivalent angular velocities [25]. An adequately high value of these indexes is likely to effectively prevent injuries of the lower limbs (including those that occur without contact) due to effective eccentric activity to slow down or stop the movement [26].

Measurements of muscle torque under isometric conditions allow for the determination of the maximum values of force generated by a given muscle group to evaluate the potential of the player, the training programme, and muscle imbalance. It should also be noted that the amount of force generated depends on many factors, including physiological and biochemical factors. The aspect of morphological determinants is also important. Previous studies have investigated the relationships of muscle torque with body mass, body mass composition, and somatotype [27-31]. However, the results of such studies have been inconclusive. Norsuriani and Ooi [31] demonstrated positive relationships between muscle torque in the knee joint and body mass, fat-free mass, and body fat. Similar results were presented by Pietraszewski et al. [27]. Lewandowska et al. [28] emphasized positive relationships of muscle torque in the lower limb joints with characteristics of muscularity and skeletal mass (mesomorphy), negative relationships with body slenderness (ectomorphy) and lack of relationships with the fat component (endomorphy). Kim et al. [29] found that men with higher skeletal muscle mass are characterized by higher isokinetic muscle torque values in the lower limb joints. Furthermore, to our knowledge, no previous studies have examined the relationships between the conventional $\mathrm{H} / \mathrm{Q}$ ratio and anthropometric variables. It should be pointed out that anthropometric measurements are the basic method used to assess the level of development of many morphological features. They can be performed anytime and anywhere, using mobile equipment. Measurements of body girths and skinfolds provide additional indirect information about changes in tissue components, which are very important in the context of functional capabilities of a player. Understanding the relationships between muscle torque and the anthropometric variables would allow coaches to easily make an initial assessment of the players' strength abilities and, at the same time, control the training effects. 
Muscle torque is the product of the force $F$ and the length of the lever arm $r$. The lever arm $r$ is understood as the distance from the axis of rotation of the lever (joint) along a line perpendicular to the direction of the force $F$. Therefore, it can be expected that the torque of the flexors and extensors of the knee joint are related to the characteristics of muscle development (girths of the body parts) and the length of the individual lower limb parts. These features are related to the overall body size but may also show interpersonal differentiation due to the modifying effect of various environmental factors, including sports training. Due to the specificity of the training, the knowledge gained from the research of players practising various sports cannot be used uncritically. Substantial values of anthropometric variables (e.g., girths of body parts) may result from both muscularity and body fat. However, due to the characteristics of the research group (soccer players) resulting from the specificity of the motor activities performed by such athletes and the usually low body fat content in lower limbs, the relationships should be expected between muscle torque and variables indirectly describing muscularity of the lower limbs. It is important to examine morphofunctional relations in a specific sport.

The aim of the study is to identify the relationships between anthropometric variables and the values of knee joint extensor peak torque, knee joint flexor peak torque, and conventional hamstring-to-quadriceps ratio in a group of Polish first-division soccer players. Furthermore, the authors intended to identify the anthropometric variables that allow for the best possible estimation of the abovementioned biomechanical variables, which would allow coaches to monitor more frequently the effect of training loads used at different stages of the annual training cycle. Knowledge of the abovementioned biomechanical variables is also important during the choice of training loads to reduce the injury risk of athletes.

\section{Materials and Methods}

The study examined 37 soccer players aged 19 to 30 years. They were players playing in the Polish Ekstraklasa league. The study included only the players who had actively participated in training and league matches since the beginning of the season and had not been injured. They were previously qualified for the examinations by a sports physician. Their mean training experience was 14 years (8 to 20 years). The mean body mass $( \pm S D)$ of the subjects was $76.8 \pm 7.2 \mathrm{~kg}$, and the body height was $1.82 \pm 0.06 \mathrm{~m}$. The tests were conducted in the morning, before the training sessions. On the day before the tests, the players did not play any league matches.

The study was carried out in the Biomechanical Analysis Laboratory and Scientific Research Laboratory of the Faculty of Sport (both with PN-EN ISO 9001:2009 certification) at the University School of Physical Education in Wrocław, Poland. All subjects gave their informed consent for inclusion before they participated in the study. The study was conducted in accordance with the Declaration of Helsinki, and the protocol was approved by the Senate's Research Bioethics Commission of the University School of Physical Education in Wrocław, Poland. Measurements were performed according to International Standards for Anthropometric Assessment (ISAK) [32].

The following anthropometric variables were measured: sitting height (B-vs), lower extremity length (B-tro), shank length (B-ti), biacromial diameter (a-a), biiliocristal diameter (ic-ic), humerus breadth (cl-cm), femur breath (epl-epm), chest girth, waist girth, hip girth, relaxed and flexed biceps girth, thigh girth, and calf girth. Skinfold thickness was measured at the subscapular, abdominal, suprailiac, triceps, and calf locations to assess body fat. Body height, lengths, and breadths were measured to the nearest $0.1 \mathrm{~cm}$ with the use of the GPM Anthropological Instruments (Siber Hegner Machinery Ltd., Zürich, Switzerland). Skinfold thickness was measured with a Tanner/Whitehouse skinfold calliper (Holtain LTD, Crosswell, Crymych, Pembs, UK) with a $0.2 \mathrm{~mm}$ graduation. Body mass was measured with an electronic weighing scale with an accuracy of $0.1 \mathrm{~kg}$. Body mass index (BMI) was also calculated.

The peak muscle torque under isometric conditions was measured to assess the strength of the lower limbs. Peak muscle torque for extensors and flexors of the knee joint was measured at $75^{\circ}$ and 
$30^{\circ}$, respectively; $0^{\circ}$ at the knee joint was considered to be a full extension. The measurements were performed separately for the right and left lower limbs. The results of measurements of the dominant limb were used for analyses. Biodex System 4 Pro (Biodex Medical Systems, Inc., Shirley, NY, USA) was used for the torque measurements. The conventional hamstring-to-quadriceps ratio (H/Q ratio) was calculated using the following equation:

$$
\mathrm{H} / \mathrm{Q} \text { ratio }=\left(T_{f} / T_{e}\right) \cdot 100 \%,
$$

where $T_{f}$ denotes the concentric peak torque value of knee joint flexors of the dominant lower limb and $T_{e}$ is the concentric peak torque value of extensors of the same joint and limb. The conventional $\mathrm{H} / \mathrm{Q}$ ratio is possible to calculate during the measurement of peak torque only under isometric conditions [33]. Furthermore, the muscle torques of extensors and flexors were added together, and the muscle torque for the knee joint relative to body mass was calculated:

$$
\left(T_{e}+T_{f}\right) / \mathrm{BM} .
$$

To supplement the information about the general strength abilities of the soccer players studied, back and handgrip strengths were measured using TAKEI dynamometers (Takei Scientific Instruments Co., Ltd., Niigata City, Japan).

Cluster analysis ( $k$-means) was used in the statistical analysis to distinguish two groups significantly differing in the magnitude of muscle torque. The intergroup differentiation of anthropometric variables in these clusters was evaluated by means of Student's $t$-test for independent samples. Pearson's $r$ correlation coefficient was used to evaluate the relationships of anthropometric variables with muscle torque.

\section{Results}

The soccer players studied were characterized by small and moderate intragroup variability in the anthropometric variables (Table 1). The mass-to-height ratios were correct and were confirmed by the BMI values in the entire group $\left(23.3 \pm 1.5 \mathrm{~kg} / \mathrm{m}^{2}\right)$.

The obtained values of muscle torque showed a clear interindividual differentiation. To create relatively homogeneous groups in terms of the values of muscle torque generated in the knee extensors and flexors, the $k$-mean cluster analysis was used to identify two subgroups significantly differing in the magnitude of these variables: Group 1-weaker group and Group 2-stronger group. With the adopted criterion of division, the groups differed significantly in terms of the generated muscle torque and in terms of the sum of muscle torque relative to body mass (Table 2). All of the above values were significantly higher in Group 2 (stronger). Higher values were also found in most of the anthropometric variables in this group of players. However, significant intergroup differences were recorded only for body mass, BMI; chest, thigh and calf girths; and humerus and femur breadths, which are a measure of skeleton size. The soccer players from Group 2 also showed significantly higher values in the remaining strength tests, although these variables were not included in the grouping variables. Both back strength and handgrip strength were greater in the athletes from the second cluster. The mean conventional $\mathrm{H} / \mathrm{Q}$ ratios were $47.0 \%$ (Group 1) and $45.6 \%$ (Group 2).

The values of correlation coefficients between muscle torque of the knee extensors and flexors and anthropometric variables were quite low, yet statistically significant in some cases (Table 3). The strongest relationships were observed for knee joint extensors with body mass, BMI, and variables describing skeleton size and lower limb muscles. In the case of the torque of knee flexors, a significant relationship was found only with body mass and BMI. However, no significant relationships were observed between the conventional $\mathrm{H} / \mathrm{Q}$ ratio and the anthropometric variables studied. 
Table 1. Statistical characterization of the variables analysed for the entire group of soccer players studied $(n=37)$.

\begin{tabular}{|c|c|c|c|c|}
\hline Variables & Mean & Minimum & Maximum & SD \\
\hline Body height $(\mathrm{cm})$ & 181.6 & 170.0 & 192.5 & 5.5 \\
\hline Body mass (kg) & 76.8 & 65.0 & 94.5 & 7.2 \\
\hline BMI $\left(\mathrm{kg} / \mathrm{m}^{2}\right)$ & 23.3 & 18.6 & 26.0 & 1.5 \\
\hline b-vs (cm) & 95.2 & 89.5 & 104.3 & 3.3 \\
\hline b-tro $(\mathrm{cm})$ & 95.6 & 88.0 & 105.2 & 4.0 \\
\hline b-ti (cm) & 48.5 & 38.5 & 54.0 & 2.7 \\
\hline $\mathrm{a}-\mathrm{a}(\mathrm{cm})$ & 41.8 & 38.0 & 46.5 & 1.8 \\
\hline ic-ic $(\mathrm{cm})$ & 28.6 & 25.4 & 32.5 & 1.8 \\
\hline $\mathrm{cl}-\mathrm{cm}(\mathrm{cm})$ & 7.1 & 6.4 & 7.8 & 0.3 \\
\hline epl-epm (cm) & 10.1 & 9.2 & 11.1 & 0.5 \\
\hline Chest girth $(\mathrm{cm})$ & 88.4 & 80.0 & 100.0 & 4.9 \\
\hline Waist girth $(\mathrm{cm})$ & 79.5 & 70.0 & 89.0 & 4.6 \\
\hline Relaxed biceps girth $(\mathrm{cm})$ & 30.3 & 26.0 & 35.0 & 2.4 \\
\hline Flexed biceps girth $(\mathrm{cm})$ & 33.4 & 29.5 & 37.5 & 2.3 \\
\hline Hip girth $(\mathrm{cm})$ & 98.5 & 90.0 & 106.0 & 3.5 \\
\hline Thigh girth $(\mathrm{cm})$ & 58.5 & 50.4 & 65.0 & 3.0 \\
\hline Calf girth $(\mathrm{cm})$ & 37.9 & 33.2 & 41.0 & 1.8 \\
\hline Subscapular skinfold (mm) & 8.2 & 5.8 & 12.0 & 1.4 \\
\hline Triceps skinfold (mm) & 4.3 & 2.8 & 7.0 & 1.0 \\
\hline Suprailiac skinfold (mm) & 6.8 & 4.6 & 12.0 & 1.7 \\
\hline Abdominal skinfold (mm) & 7.0 & 4.0 & 12.0 & 2.2 \\
\hline Calf skinfold (mm) & 3.7 & 2.8 & 5.4 & 0.7 \\
\hline Right hand grip strength (kG) & 47.5 & 36.0 & 62.0 & 6.3 \\
\hline Left hand grip strength $(\mathrm{kG})$ & 46.2 & 38.0 & 58.0 & 5.2 \\
\hline Back strength $(\mathrm{kG})$ & 127.0 & 91.5 & 169.5 & 18.7 \\
\hline$T_{e}(\mathrm{Nm})$ & 416.8 & 252.7 & 596.7 & 86.4 \\
\hline$T_{f}(\mathrm{Nm})$ & 191.7 & 106.0 & 294.4 & 46.3 \\
\hline $\mathrm{H} / \mathrm{Q}$ ratio $(\%)$ & 46.1 & 32.1 & 61.0 & 6.5 \\
\hline$\left(T_{e}+T_{f}\right) / \mathrm{BM}(\mathrm{Nm} / \mathrm{kg})$ & 7.9 & 5.5 & 12.1 & 1.5 \\
\hline
\end{tabular}

SD—standard deviation; BMI—body mass index; b-vs—sitting height; b-tro-lower extremity length; b-ti—shank length; a-a_biacromial diameter; ic-ic — biiliocristal diameter; cl-cm—humerus breadth; epl-epm—-femur breath; $T_{e}$ - peak torque value of knee joint extensors; $T_{f}$ - peak torque value of knee joint flexors; $\mathrm{H} / \mathrm{Q}$ ratio-conventional hamstrings-to-quadriceps ratio; $\left(T_{e}+T_{f}\right)$ / BM-sum of knee muscle torque relative to body mass.

Table 2. Statistical characteristics of the variables studied in separate clusters.

\begin{tabular}{|c|c|c|c|c|}
\hline Variables & $\begin{array}{c}\text { Group } 1 \text { (weaker) } \\
n=14\end{array}$ & $\begin{array}{c}\text { Group } 2 \text { (stronger) } \\
n=23\end{array}$ & $t$ & $p$ \\
\hline Body height $(\mathrm{cm})$ & $180.5 \pm 5.0$ & $182.2 \pm 5.8$ & -0.95 & 0.349 \\
\hline Body mass (kg) & $72.8 \pm 5.1$ & $79.2 \pm 7.3$ & -2.91 & 0.006 * \\
\hline BMI $\left(\mathrm{kg} / \mathrm{m}^{2}\right)$ & $22.4 \pm 1.5$ & $23.8 \pm 1.3$ & -3.13 & 0.004 * \\
\hline b-vs (cm) & $94.7 \pm 2.8$ & $95.6 \pm 3.5$ & -0.86 & 0.395 \\
\hline b-tro $(\mathrm{cm})$ & $95.6 \pm 4.0$ & $95.7 \pm 4.0$ & -0.06 & 0.951 \\
\hline $\mathrm{b}-\mathrm{ti}(\mathrm{cm})$ & $48.4 \pm 2.1$ & $48.5 \pm 3.1$ & -0.07 & 0.945 \\
\hline $\mathrm{a}-\mathrm{a}(\mathrm{cm})$ & $41.3 \pm 1.8$ & $42.1 \pm 1.9$ & -1.33 & 0.191 \\
\hline ic-ic $(\mathrm{cm})$ & $28.4 \pm 1.5$ & $28.8 \pm 2.0$ & -0.77 & 0.447 \\
\hline $\mathrm{cl}-\mathrm{cm}(\mathrm{cm})$ & $7.0 \pm 0.3$ & $7.2 \pm 0.3$ & -2.60 & 0.014 * \\
\hline epl-epm (cm) & $9.9 \pm 0.3$ & $10.2 \pm 0.5$ & -1.52 & 0.037 * \\
\hline Chest girth $(\mathrm{cm})$ & $86.6 \pm 5.2$ & $89.6 \pm 4.4$ & -1.83 & 0.076 \\
\hline Waist girth $(\mathrm{cm})$ & $78.0 \pm 4.0$ & $80.4 \pm 4.9$ & -1.55 & 0.131 \\
\hline Relaxed biceps girth $(\mathrm{cm})$ & $29.8 \pm 1.6$ & $30.7 \pm 2.7$ & -1.15 & 0.260 \\
\hline Flexed biceps girth $(\mathrm{cm})$ & $33.1 \pm 1.8$ & $33.6 \pm 2.6$ & -0.67 & 0.505 \\
\hline Hip girth $(\mathrm{cm})$ & $97.3 \pm 2.7$ & $99.3 \pm 3.8$ & -1.74 & 0.091 \\
\hline Thigh girth $(\mathrm{cm})$ & $57.1 \pm 2.8$ & $59.3 \pm 2.8$ & -2.29 & 0.028 * \\
\hline Calf girth $(\mathrm{cm})$ & $36.9 \pm 2.0$ & $38.5 \pm 1.4$ & -2.83 & 0.008 * \\
\hline Subscapular skinfold (mm) & $7.5 \pm 1.1$ & $8.5 \pm 1.5$ & -2.15 & 0.039 * \\
\hline Triceps skinfold $(\mathrm{mm})$ & $4.4 \pm 1.3$ & $4.2 \pm 0.9$ & 0.36 & 0.719 \\
\hline Suprailiac skinfold (mm) & $6.1 \pm 1.1$ & $7.2 \pm 1.9$ & -1.97 & 0.057 \\
\hline Abdominal skinfold (mm) & $6.4 \pm 1.8$ & $7.4 \pm 2.3$ & -1.29 & 0.206 \\
\hline Calf skinfold (mm) & $3.5 \pm 0.5$ & $3.9 \pm 0.7$ & -1.95 & 0.060 \\
\hline Right hand grip strength (kG) & $44.4 \pm 5.5$ & $49.4 \pm 6.1$ & -2.53 & 0.016 * \\
\hline Left hand grip strength $(\mathrm{kG})$ & $43.6 \pm 4.6$ & $47.8 \pm 4.9$ & -2.56 & 0.015 * \\
\hline Back strength $(\mathrm{kG})$ & $112.4 \pm 11.9$ & $135.9 \pm 16.5$ & -4.62 & 0.000 * \\
\hline$T_{e}(\mathrm{Nm})$ & $325.6 \pm 37.2$ & $472.2 \pm 53.9$ & -8.93 & 0.000 * \\
\hline$T_{f}(\mathrm{Nm})$ & $152.3 \pm 26.1$ & $215.6 \pm 39.0$ & -5.37 & 0.000 * \\
\hline $\mathrm{H} / \mathrm{Q}$ ratio & $47.0 \pm 7.4$ & $45.6 \pm 6.0$ & 0.61 & 0.546 \\
\hline$\left(T_{e}+T_{f}\right) / \mathrm{BM}(\mathrm{Nm} / \mathrm{kg})$ & $6.6 \pm 1.3$ & $8.7 \pm 0.8$ & -5.60 & 0.000 * \\
\hline
\end{tabular}

* - significant differences between Groups I and II group at the level of $p<0.05 ; p$-probability of type I error; $t$ - $t$-test value; BMI—body mass index; b-vs—sitting height; b-tro—lower extremity length; $\mathrm{b}$-ti —shank length; a-a_biacromial diameter; ic-ic - biiliocristal diameter; cl-cm — humerus breadth; epl-epm — femur breath; $T_{e}$ — peak torque value of knee joint extensors; $T_{f}$ - peak torque value of knee joint flexors; $H / Q$ ratio-conventional hamstrings-to-quadriceps ratio; $\left(T_{e}+T_{f}\right) / \mathrm{BM} \longrightarrow$ sum of knee muscle torques relative to body mass. 
Table 3. The correlation coefficients between the muscle torque of extensors $\left(T_{e}\right)$ and flexors $\left(T_{f}\right)$ of the knee joint and anthropometric variables for the entire group of soccer players $(n=37)$.

\begin{tabular}{cccccc}
\hline Anthropometric Variables & $T_{\boldsymbol{e}}$ & $T_{f}$ & Anthropometric Variables & $T_{\boldsymbol{e}}$ & $T_{f}$ \\
\hline Body height & 0.21 & 0.12 & Flexed biceps girth & 0.10 & 0.06 \\
Body mass & $0.46^{*}$ & $0.34^{*}$ & Hip girth & 0.26 & 0.13 \\
BMI & $0.45^{*}$ & $0.37^{*}$ & Thigh girth & 0.26 & 0.20 \\
b-vs & 0.21 & 0.18 & Calf girth & $0.40^{*}$ & 0.31 \\
b-tro & 0.14 & -0.01 & Subscapular skinfold & $0.34^{*}$ & 0.14 \\
b-ti & 0.07 & -0.09 & Triceps skinfold & 0.12 & 0.12 \\
a-a & 0.16 & -0.02 & Suprailiac skinfold & $0.36^{*}$ & 0.23 \\
ic-ic & 0.16 & 0.05 & Abdominal skinfold & 0.19 & 0.14 \\
cl-cm & $0.34^{*}$ & 0.21 & Calf skinfold & $0.38^{*}$ & 0.29 \\
epl-epm & $0.43^{*}$ & 0.22 & Right handgrip strength & $0.33^{*}$ & 0.27 \\
Chest girth & 0.31 & 0.13 & Left handgrip strength & $0.35^{*}$ & 0.26 \\
Waist girth & 0.27 & 0.08 & Back strength & $0.56^{*}$ & 0.25 \\
Relaxed biceps girth & 0.27 & 0.17 & & &
\end{tabular}

*- statistically significant at $p<0.05$; BMI—body mass index; b-vs—sitting height; b-tro-lower extremity length; b-ti-shank length; a-a-biacromial diameter; ic-ic—biiliocristal diameter; cl-cm-humerus breadth; epl-epm-femur breath.

Multiple regression analysis was performed, taking into account body height and anthropometric variables that were most significantly correlated with the examined muscle torque. A significant effect of anthropometric variables on the muscle torque measured in the knee joint was demonstrated. A regression model with four anthropometric variables estimating the biomechanical values was statistically significant, and all predictors explained $38 \%$ of the torque variation in the knee extensors and $25 \%$ of the torque variation in the knee flexors. Three of the four predictors in the model had a significant effect on the torque of the knee extensors and flexors. The results of the regression analysis are presented in Tables 4 and 5. The estimation error for the extensor Equation (3) was 72.3, whereas for the flexor Equation (4), this value was 42.5.

$$
\begin{aligned}
T_{e}= & 1943.845-(10.052 \cdot \text { body height })-(25.424 \cdot \text { thigh girth })+(13.383 \cdot \text { calf girth })+(16.652 \cdot \text { body mass }) . \\
& T_{f}=1019.404-(5204 \cdot \text { body height })-(11,878 \cdot \text { thigh girth })+(5715 \cdot \text { calf girth })+(7756 \cdot \text { body mass }) .
\end{aligned}
$$

\begin{tabular}{|c|c|c|c|c|}
\hline \multirow[t]{2}{*}{ Independent Variables } & \multicolumn{4}{|c|}{$\begin{array}{l}\text { Dependent Variable: Peak Torque Value of Knee Joint Extensors } \\
\qquad \begin{array}{c}R=0.62, R^{2}=0.38, \mathrm{Adj} . R^{2}=0.30 \\
F(4.32)=4.86, p<0.01 \\
\text { Standard Error of the Estimate: } 72.3\end{array}\end{array}$} \\
\hline & $b$ & $\begin{array}{c}\text { Standard Error of } \\
b\end{array}$ & $t$ & $p$ \\
\hline Intercept coefficient* & 1943.9 & 880.1 & 2.2 & 0.035 \\
\hline Body height * & -10.1 & 4.3 & -2.4 & 0.025 \\
\hline Thigh girth * & -25.4 & 9.4 & -2.7 & 0.011 \\
\hline Calf girth & 13.4 & 9.8 & 1.4 & 0.180 \\
\hline Body mass* & 16.7 & 5.1 & 3.3 & 0.003 \\
\hline
\end{tabular}

Table 4. Results of regression analysis for knee joint extensor torque.

\begin{tabular}{|c|c|c|c|c|}
\hline \multirow[t]{2}{*}{ Independent Variables } & \multicolumn{4}{|c|}{$\begin{array}{l}\text { Dependent Variable: Peak Torque Value of Knee Joint Flexors } \\
\qquad R=0.50, R^{2}=0.25, \mathrm{Adj} . R^{2}=0.16 \\
F(4.32)=2.71, p<0.05 \\
\text { Standard Error of the Estimate: } 42.5\end{array}$} \\
\hline & $b$ & $\begin{array}{c}\text { Standard Error of } \\
b\end{array}$ & $t$ & $p$ \\
\hline Intercept coefficient & 1019.4 & 516.7 & 2.0 & 0.057 \\
\hline Body height * & -5.2 & 2.5 & -2.1 & 0.047 \\
\hline Thigh girth * & -11.9 & 5.5 & -2.2 & 0.038 \\
\hline Calf girth & 5.7 & 5.7 & 1.0 & 0.326 \\
\hline Body mass* & 7.8 & 3.0 & 2.6 & 0.015 \\
\hline
\end{tabular}

Table 5. Results of regression analysis for knee joint flexor torque. 


\section{Discussion}

The body build of the soccer players studied showed a typical profile of basic anthropometric variables typical for athletes participating in this sport. Interpersonal differences resulted from the different playing positions $[34,35]$. The mean body height of the soccer players studied $(1.82 \pm 0.06 \mathrm{~m})$ was similar to the mean body height of the players of most of the best teams in the world and slightly exceeds the mean body height of young men in Poland $(1.79 \pm 0.07 \mathrm{~m})$ [36]. Therefore, the results obtained in the study are consistent with the information provided in the literature on the body morphology of athletes. Norton and Olds [32] indicated that the mean body height of soccer players $(1.79 \pm 0.06 \mathrm{~m})$ and its variations are very close to those of the general population. This finding was also confirmed by the research presented by Reilly and Doran [17]. However, these authors pointed to differences depending on sports skill level and nationality. The extreme values in their ranking were obtained from the players from Hong Kong $(1.73 \pm 0.06 \mathrm{~m})$ and Norway $(1.81 \pm 0.05 \mathrm{~m})$. The BMI of soccer players in the present study also showed values typical of soccer players [17]. The athletes tested were characterized by good musculature of all body parts, as evidenced by the values of chest and lower and upper limb girths. These features are similar to those of players on other soccer teams [34,35]. The results of our research indicated particularly muscular thighs, which enable players to generate high muscle torque. This ability is also very important when jumping, kicking, rotating, and changing the velocity of movement $[14,17,19]$. The harmonious development of limb and torso muscles contributes to maintaining player balance on a slippery field and allows for easier control of the ball [17]. Particularly valuable research, whose results can help athletes achieve top-level performance, was carried out among the players of the top teams. Therefore, it seems very valuable that we had an opportunity to conduct research on the Polish first-division soccer players.

Analysis of the muscle torque of knee extensors and flexors shows that human muscles are shaped to a large extent by the gravitational field. This finding is reflected in the significant muscle torque of the knee joint extensors $(416.8 \pm 86.4 \mathrm{Nm})$, which act against the gravitational force. The torque values of the knee flexors are approximately two times lower $(191.7 \pm 46.3 \mathrm{Nm})$. The mean values of isometric muscle torque in the knee joint obtained for the players in our study are much higher than the mean values obtained in Polish striker soccer players ( $315.3 \pm 53.3 \mathrm{Nm}$ for extensors and $167.7 \pm 26.0 \mathrm{Nm}$ for flexors) [37] and higher than those in lower-league soccer players (328.0 $\pm 69.7 \mathrm{Nm}$ for extensors) [38]. The recorded large values of isometric muscle torque measured in our study may result from substantial training loads to which players were exposed. They trained four times a week in two sessions. In the morning, the athletes had a soccer training session (about 2.5 hours). In the afternoon, they exercised in the gym for about 1.5 hours. The exercises were selected individually. The high sports skill level of the players studied is also of great importance to the results obtained. Previous studies $[1,39]$ indicated differences in the magnitude of muscle torque depending on the sports skill level. Measurements of muscle torque under isokinetic conditions are now also popular. However, these measurements have limitations $[33,40]$. Furthermore, the aim of the study was to determine the maximum strength abilities of the players, rather than the strength at a certain angular velocity of movement in the knee joint.

The relationship between the muscle torque of extensors and flexors of the knee joint is important from the standpoint of maintaining knee stability during some movement activities. For example, damage to the hamstrings can occur during the kicking of the ball with the lower limb. This damage may occur when, during knee extension, a group of antagonistic muscles does not ensure the effective eccentric deceleration of the movement $[8,41,42]$. It is assumed that conventional $\mathrm{H} / \mathrm{Q}$ ratio values exceeding $60 \%$ can effectively prevent injuries and damage to the anterior cruciate ligament (ACL) and hamstring strains [43-48]. According to Kim and Hong [44], soccer players with a conventional H/Q ratio of more than $60 \%$ are less likely to suffer non-contact injuries to their lower limbs. In this study, the conventional $\mathrm{H} / \mathrm{Q}$ ratio was $46.1 \%$ for all the soccer players studied, which is lower than the desired value and indicates unfavourable proportions of muscle torque in these muscle groups. This result suggests that coaches should pay more attention to the improvement of the strength level of the knee 
flexors during training. No injuries were reported the last time among the players studied. However, it can be presumed that this was influenced by motor control, which means mutual adjustment of the musculoskeletal and nervous systems [49]. In order to control movement, the central nervous system must integrate multiple sensory information (both external and proprioceptive) and trigger the signals necessary for muscle recruitment to achieve the intended goal. The performance of the movement consists in the planning of the motor strategy and its economic and flawless execution. Disturbed motor control has a negative effect on the quality of movement and increases the risk of injury. It should be expected that in elite players, sport training had led to the improved motor control. Disproportionate torque of agonist and antagonist muscle groups has been observed in male soccer players $[27,37,48]$. However, there are groups of soccer players for which the value of the conventional $\mathrm{H} / \mathrm{Q}$ ratio remains within the recommended standard [45]. Cometti et al. [39] demonstrated that sports skill level in soccer players increases with higher $\mathrm{H} / \mathrm{Q}$ ratios.

The lack of significant relationships between the conventional $\mathrm{H} / \mathrm{Q}$ ratio and anthropometric variables indicates that low values of the conventional $\mathrm{H} / \mathrm{Q}$ ratio in the group of soccer players (i.e., not entirely correct proportion of torque of antagonistic muscle groups) cannot be observed based on the variables describing body structure. Therefore, muscle imbalance cannot be diagnosed without special biomechanical measurements because the body build will not suggest such an abnormality. It should also be noted that high $\mathrm{H} / \mathrm{Q}$ ratios may exist in the presence of relative weakness in both the hamstring and quadriceps muscle groups [50], which can also explain the lack of the above relationships. Another limitation may be that the peak values of extensors and flexors occur at different knee flexion angles [26,33].

Dividing the soccer players studied into two clusters allowed for the assessment of body build differences between the players, who significantly differed in terms of muscle torque generated within the knee joint. The athletes from both clusters did not show any differences in body height or its components, which is attributable to the genetic determinants of this feature [51]. Furthermore, the differences observed in body mass and girths that describe the size of the skeleton and muscles indicate relationships between these features and strength abilities. This is also confirmed by significant correlation coefficients for some anthropometric features (body mass, humerus breadth, femur breadth, calf girth, subscapular skinfold, suprailiac skinfold, and calf skinfold) and isometric muscle torque of the knee joint extensors and flexors. As in other studies, positive relationships were obtained between muscle torque and body mass, breadths and girths that describe the size of the skeleton and muscles [27-31]. However, contrary to previous reports, positive relationships between muscle torque and skinfolds were also found [28].

The regression analysis was used to identify the variables that can be indirectly used to estimate torque values for knee joint extensors and flexors generated by the player. The results of this analysis identify the body height, body mass, and thigh and calf girth as the features that best describe these variables. Therefore, based on these anthropometric variables, the coach may initially assess the strength abilities of soccer players, and these assessments can lead to the adjustment of training programmes to the individual predispositions of the players.

The limitations of our study are incomplete information about the applied training loads (resulting, e.g., from club changes of the players studied), the sex of the players (slightly different results can be expected in female groups, which are characterized by higher body fat), and the type of sport being practised (it is not advisable to directly refer to the results of people practising other sports, e.g., individual sports). On the other hand, all of the players studied belonged to the national soccer elite, which allows for the assumption that their training was carried out professionally, translating into a high sports skill level.

\section{Conclusions}

The results allow for the conclusion that the muscle torque of the knee joint extensors and flexors in soccer players is significantly related to some anthropometric variables. Due to the less complicated 
nature of anthropometric apparatuses and the high mobility of this type of equipment, the prediction of muscle torque in the knee joint based on anthropometry seems to be useful for screening soccer players for preliminary estimation of the abovementioned biomechanical variables. However, anthropometric methods do not provide full information about the mutual relationships between the muscle torque of the knee joint extensors and flexors, which is very important from the standpoint of injury prevention. For this reason, measurements using special biomechanical equipment are also necessary for the comprehensive analyses and control of the effects of sports training.

Author Contributions: Conceptualization, J.P. and B.P.; methodology, J.P. and B.P.; software, J.P. and B.P.; validation, J.P., A.S. (Artur Struzik), A.B., A.S (Aleksandra Stachoń). and B.P.; formal analysis, J.P., A.S. (Artur Struzik) and B.P.; investigation, J.P., A.B., A.S. (Aleksandra Stachoń) and B.P.; resources, J.P., A.B., A.S. (Aleksandra Stachoń) and B.P.; data curation, J.P. and A.S. (Artur Struzik); writing-original draft preparation, J.P., A.S. (Artur Struzik) and B.P.; writing-review and editing, J.P., A.S. (Artur Struzik) and B.P.; visualization, J.P. and A.S. (Artur Struzik); supervision, J.P.; project administration, J.P.; and funding acquisition, B.P. All authors have read and agreed to the published version of the manuscript.

Funding: This research received no external funding.

Acknowledgments: The authors thank the study participants for their effort, time devotion, and collaboration during the study.

Conflicts of Interest: The authors declare no conflict of interest. The funders had no role in the design of the study; in the collection, analyses, or interpretation of data; in the writing of the manuscript; or in the decision to publish the results.

\section{References}

1. Wit, A.; Eliasz, J.; Gajewski, J.; Janiak, J.; Jaszczuk, J.; Trzaskoma, Z. Maximal isometric muscle torque assessment in elite athletes. Acta Bioeng. Biomech. 2002, 4, 591-592.

2. Ergün, M.; Işlegen, C.; Taşkiran, E. A cross-sectional analysis of sagittal knee laxity and isokinetic muscle strength in soccer players. Int. J. Sports Med. 2004, 25, 594-598. [CrossRef] [PubMed]

3. Zakas, A. Bilateral isokinetic peak torque of quadriceps and hamstring muscles in professional soccer players with dominance on one or both two sides. J. Sports Med. Phys. Fitness 2006, 46, 28-35. [PubMed]

4. Ellenbecker, T.S.; Roetert, E.P.; Sueyoshi, T.; Riewald, S. A descriptive profile of age-specific knee extension flexion strength in elite junior tennis players. Br. J. Sports Med. 2007, 41, 728-732. [CrossRef]

5. Ruas, C.V.; Minozzo, F.; Pinto, M.D.; Brown, L.E.; Pinto, R.S. Lower-extremity strength ratios of professional soccer players according to field position. J. Strength Cond. Res. 2015, 29, 1220-1226. [CrossRef]

6. Lech, G.; Chwała, W.; Ambroży, T.; Sterkowicz, S. Muscle torque and its relation to technique, tactics, sports level and age group in judo contestants. J. Hum. Kinet. 2015, 45, 167-175. [CrossRef]

7. Sterkowicz, S.; Lech, G.; Sterkowicz-Przybycień, K.; Chwała, W.; Ambroży, T.; Pałka, T. Relationship of maximal isometric torque produced in flexors and extensors rate to technique by judo athletes. Acta Bioeng. Biomech. 2018, 20, 65-71.

8. Croisier, J.L.; Ganteaume, S.; Binet, J.; Genty, M.; Ferret, J.M. Strength imbalances and prevention of hamstring injury in professional soccer players: A prospective study. Am. J. Sports Med. 2008, 36, 1469-1475. [CrossRef]

9. Ruas, V.C.; McManus, T.R.; Bentes, M.C.; Costa, B.P. Acute effects of proprioceptive neuromuscular facilitation on peak torque and muscle imbalance. J. Funct. Morphol. Kinesiol. 2018, 3, 63. [CrossRef]

10. Bamaç, B.; Çolak, T.; Özbek, A.; Çolak, S.; Cinel, Y.; Yenigün, Ö. Isokinetic performance in elite volleyball and basketball players. Kinesiology 2008, 40, 183-189.

11. Hadzic, V.; Sattler, T.; Markovic, G.; Veselko, M.; Dervisevic, E. The isokinetic strength profile of quadriceps and hamstrings in elite volleyball players. Isokinet. Exerc. Sci. 2010, 18, 31-37. [CrossRef]

12. Teixeira, J.; Carvalho, P.; Moreira, C.; Carneiro, A.; Santos, R. Muscle strength assessment of knee flexors and extensors. Comparative study between basketball, football, handball and volleyball athletes. Int. J. Sports Sci. 2015, 5, 192-200.

13. Jones, P.A.; Thomas, C.; Dos'Santos, T.; McMahon, J.J.; Graham-Smith, P. The role of eccentric strength in $180^{\circ}$ turns in female soccer players. Sports 2017, 5, 42. [CrossRef] [PubMed]

14. Struzik, A.; Pietraszewski, B. Relationships between hamstrings-to-quadriceps ratio and variables describing countermovement and drop jumps. Appl. Bionics Biomech. 2019, 2019, 4505481. [CrossRef] [PubMed] 
15. Zatsiorsky, V.M.; Kraemer, W.J. Science and Practice of Strength Training, 2nd ed.; Human Kinetics: Champaign, IL, USA, 2006; pp. 17-46.

16. Reilly, T.; Bangsbo, J.; Franks, A. Anthropometric and physiological predispositions for elite soccer. J. Sports Sci. 2000, 18, 669-683. [CrossRef] [PubMed]

17. Reilly, T.; Doran, D. Fitness assessment. In Science and Soccer; Reilly, T., Williams, A.M., Eds.; Routledge: London, UK; New York, NY, USA, 2003; pp. 21-46.

18. Pietraszewski, B.; Siemieński, A.; Bober, T.; Struzik, A.; Rutkowska-Kucharska, A.; Nosal, J.; Rokita, A. Lower extremity power in female soccer athletes: A pre-season and in-season comparison. Acta Bioeng. Biomech. 2015, 17, 129-135.

19. Bona, C.C.; Filho, H.T.; Izquierdo, M.; Ferraz, R.M.P.; Marques, M.C. Peak torque and muscle balance in the knees of young U-15 and U-17 soccer athletes playing various tactical positions. J. Sports Med. Phys. Fitness 2017, 57, 923-929.

20. Zago, M.; Sforza, C.; Dolci, C.; Tarabini, M.; Galli, M. Use of machine learning and wearable sensors to predict energetics and kinematics of cutting maneuvers. Sensors 2019, 19, 3094. [CrossRef]

21. Newman, M.A.; Tarpenning, K.M.; Marino, F.E. Relationships between isokinetic knee strength, single-sprint performance, and repeated-sprint ability in football players. J. Strength Cond. Res. 2004, 18, 867-872.

22. Stølen, T.; Chamari, K.; Castagna, C.; Wisløff, U. Physiology of soccer: An update. Sports Med. 2005, 35, 501-536. [CrossRef]

23. Cerrah, A.O.; Gungor, E.O.; Soylu, A.R.; Ertan, H.; Lees, A.; Bayrak, C. Muscular activation patterns during the soccer in-step kick. Isokinet. Exerc. Sci. 2011, 19, 181-190. [CrossRef]

24. Dvir, Z.; Eger, G.; Halperin, N.; Shklar, A. Thigh muscle activity and anterior cruciate ligament insufficiency. Clin. Biomech. 1989, 4, 87-91. [CrossRef]

25. Aagaard, P.; Simonsen, E.B.; Magnusson, S.P.; Larsson, B.; Dyhre-Poulsen, P. A new concept for isokinetic hamstring: Quadriceps muscle strength ratio. Am. J. Sports Med. 1998, 26, 231-237. [CrossRef] [PubMed]

26. Struzik, A.; Siemieński, A.; Bober, T.; Pietraszewski, B. Ratios of torques of antagonist muscle groups in female soccer players. Acta Bioeng. Biomech. 2018, 20, 153-158.

27. Pietraszewski, B.; Zawadzki, J.; Pietraszewska, J.; Burdukiewicz, A. Body composition and muscle torques of lower limbs. Biol. Sport 1997, 14, 104-107.

28. Lewandowska, J.; Buśko, K.; Pastuszak, A.; Boguszewska, K. Somatotype variables related to muscle torque and power in judoists. J. Hum. Kinet. 2011, 30, 21-28. [CrossRef]

29. Kim, S.E.; Hong, J.; Cha, J.Y.; Park, J.M.; Eun, D.; Yoo, J.; Jee, Y.S. Relative appendicular skeletal muscle mass is associated with isokinetic muscle strength and balance in healthy collegiate men. J. Sports Sci. 2016, 34, 2114-2120. [CrossRef]

30. Camic, C.L.; Housh, T.J.; Mielke, M.; Zuniga, J.; Hendrix, C.; Johnson, G.O.; Housh, D.J.; Schmidt, R.J. Validity of fat-free weight equations for predicting isokinetic peak torque in young wrestlers. Int. J. Sport Sci. Health 2018, 5, 69-78.

31. Norsuriani, S.; Ooi, F. Bone health status, isokinetic muscular strength and power, and body composition of Malay adolescent female silat and taekwondo practitioners. Int. J. Public Health Clin. Sci. 2018, 5, 244-262.

32. Norton, K.; Olds, T. Anthropometrica: A Textbook of Body Measurement for Sports and Health Courses; UNSW Press: Sydney, Australia, 2002.

33. Cozette, M.; Leprêtre, P.-M.; Doyle, C.; Weissland, T. Isokinetic strength ratios: Conventional methods, current limits and perspectives. Front. Physiol. 2019, 10, 567. [CrossRef]

34. Matković, B.R.; Mišigoj-Duraković, M.; Matković, B.; Janković, S.; Ružić, L.; Leko, G.; Kondrič, M. Morphological differences of elite Croatian soccer players according to the team position. Coll. Antropol. 2003, 27, 167-174. [PubMed]

35. Hazir, T. Physical characteristics and somatotype of soccer players according to playing level and position. J. Hum. Kinet. 2010, 26, 83-95. [CrossRef]

36. Kulaga, Z.; Litwin, M.; Tkaczyk, M.; Różdżyńska, A.; Barwicka, K.; Grajda, A.; Świąder, A.; Gurzkowska, B.; Napieralska, E.; Pan, H. The height-, weight-, and BMI-for-age of Polish school-aged children and adolescents relative to international and local growth references. BMC Public Health 2010, 10, 109. [CrossRef] [PubMed]

37. Buśko, K.; Górski, M.; Nikolaidis, P.T.; Mazur-Różycka, J.; Łach, P.; Staniak, Z.; Gajewski, J. Leg strength and power in Polish striker soccer players. Acta Bioeng. Biomech. 2018, 20, 109-116. 
38. Váczi, M.; Tollár, J.; Meszler, B.; Juhász, I.; Karsai, I. Short-term high intensity plyometric training program improves strength, power and agility in male soccer players. J. Hum. Kinet. 2013, 36, 17-26. [CrossRef]

39. Cometti, G.; Maffiuletti, N.A.; Pousson, M.; Chatard, J.C.; Maffulli, N. Isokinetic strength and anaerobic power of elite, subelite and amateur French soccer players. Int. J. Sports Med. 2001, 22, 45-51. [CrossRef]

40. Zawadzki, J.; Bober, T.; Siemieński, A. Validity analysis of the biodex system 3 dynamometer under static and isokinetic conditions. Acta Bioeng. Biomech. 2010, 12, 25-32.

41. Struzik, A.; Pietraszewski, B.; Bober, T. The biodex system used in the evaluation of the proportion of muscle torque and hamstring muscle injury risk. Pol. J. Sports Med. 2015, 1, 11-17.

42. Chen, Y.; Li, J.X.; Hong, Y.; Wang, L. Plantar stress-related injuries in male basketball players: Variations on plantar loads during different maximum-effort maneuvers. Biomed. Res. Int. 2018, 2018, 4523849. [CrossRef]

43. Hewett, T.E.; Myer, G.D.; Zazulak, B.T. Hamstrings to quadriceps peak torque ratios diverge between sexes with increasing isokinetic angular velocity. J. Sci. Med. Sport 2008, 11, 452-459. [CrossRef]

44. Kim, D.; Hong, J. Hamstring to quadriceps strength ratio and noncontact leg injuries: A prospective study during one season. Isokinet. Exerc. Sci. 2011, 19, 1-6. [CrossRef]

45. Cheung, R.T.; Smith, A.W.; Wong del, P. H:Q ratios and bilateral leg strength in college field and court sports players. J. Hum. Kinet. 2012, 33, 63-71. [CrossRef] [PubMed]

46. Dervišević, E.; Hadžić, V. Quadriceps and hamstrings strength in team sports: Basketball, football and volleyball. Isokinet. Exerc. Sci. 2012, 20, 293-300. [CrossRef]

47. Orchard, J.W.; Driscoll, T.; Seward, H.; Orchard, J.J. Relationship between interchange usage and risk of hamstring injuries in the Australian Football League. J. Sci. Med. Sport 2012, 15, 201-206. [CrossRef] [PubMed]

48. Daneshjoo, A.; Rahnama, N.; Mokhtar, A.H.; Yusof, A. Bilateral and unilateral asymmetries of isokinetic strength and flexibility in male young professional soccer players. J. Hum. Kinet. 2013, 36, 45-53. [CrossRef]

49. Latash, M. Fundamentals of Motor Control; Academic Press: Amsterdam, The Netherlands, 2012.

50. Wilkerson, G.B.; Colston, M.A.; Short, N.I.; Neal, K.L.; Hoewischer, P.E.; Pixley, J.J. Neuromuscular changes in female collegiate athletes resulting from a plyometric jump-training program. J. Athl. Train. 2004, 39, $17-23$.

51. Silventoinen, K.; Kaprio, J.; Lahelma, E.; Koskenvuo, M. Relative effect of genetic and environmental factors on body height: Differences across birth cohorts among Finnish men and women. Am. J. Public Health 2000, $90,627-630$. 